\title{
Neue Methoden zur spezifischen Bestimmung von Fibrinspaltprodukten (D-Dimere)
}

\author{
K.-E. Stötzer*, J. Amiral**, E. Spanuth* \\ - Boehringer-Mannheim GmbH, Abteilung Blutgerinnung, Mannheim \\ * Diagnostica Stago, Asnièrès, France
}

\begin{abstract}
Zusammenfassung:
Es werden zwei immunologische Bestimmungsmethoden, ein semiquantitativer Latex-Agglutinationstest (D-Dimer-Test) und ein quantitativer Enzymimmunoassay (ELISA D-Dimer) vorgestellt und hinsichtlich Spezifität und Empfindlichkeit sowie Präzision und Richtigkeit in einem Methodenvergleich untersucht.

Beide Tests basieren auf monoklonalen Antikörpern gegen das Fibrinfragment D-Dimer. Kreuzreaktionen mit Fibrinogen und den Fibrin(ogen)-Spaltprodukten $X, Y$ und $E$ sind nicht nachweisbar. Eine geringfügige Kreuzreaktion mit dem Fragment $D$ wird als vernachlässigbar angesehen. Die untere Nachweisgrenze des $D$-Dimer-Tests (Latex-Agglutination) liegt bei $0,5 \mu \mathrm{g} / \mathrm{ml}$ Fibrinogenäquivalent (Normal: $<0,5 \mu \mathrm{g} / \mathrm{ml}$ ). Wie die Untersuchungsergebnisse mit mehreren Reagenz-Chargen in verschiedenen D-Dimer-Konzentrationsbereichen zeigen, unterliegen Empfindlichkeit und Reproduzierbarkeit keinen chargenabhängigen Schwankungen. Der Methodenvergleich D-Dimer-Test/Dimertest Latex zeigt zwar eine gute Übereinstimmung beider Methoden, jedoch ist mit D-Dimer-Test eine differenziertere Aussage im Entscheidungsbereich normal-pathologisch möglich. Die Durchführung des D-Dimer-Test ist schnell (3 min) und zeichnet sich insbesondere durch die einfache und eindeutige Ablesbarkeit der Latex-Agglutination aus, so daß eine sichere und zweifelsfreie Befundung auch bei erstmaliger Anwendung oder wechselndem Personal im Nacht- oder Notfallabor gewährleistet ist. Mit ELISA-D-Dimer werden Konzentrationen ab $0,5 \mathrm{ng} / \mathrm{ml}$ Fibrinogenäquivalent zuverlässig erfaßt. In allen Konzentrationsbereichen ergeben sich im Methodenvergleich gute Übereinstimmungen mit dem D-Dimer-Test und dem Dimertest EIA. Mit einem Variationskoeffizienten von 1,6 bis 2,1\% in der Serie und 2,6 bis 4,1\% von Tag zu Tag kann auf eine gute Zuverlässigkeit der ELISA-D-DimerMethode geschlossen werden. Durch die Möglichkeit, verschiedene Trägermaterialien einzusetzen, ist die Methode an unterschiedliche Gerätesysteme applizierbar und erlaubt so eine flexible Anwendung in der Praxis.
\end{abstract}

Schlüsse/wörter:

Monoklonale Antikörper - D-Dimer - Latex-Agglutinationstest - ELISA - intravasale Gerinnungsaktivierung

\section{Summary:}

Two immunological determination methods, a semi-quantitative latex agglutination test (D-Dimer Test) and a quantitative enzyme-immunoassay (ELISA D-Dimer), are presented and investigated with regard to specificity, sensitivity, precision and accuracy in a method-comparison.

Both tests are based on monoclonal antibodies to the D-Dimer fibrin fragment. No cross-reactions with fibrinogen and the fibrin(ogen) degradation products $X, Y$ and $E$ are detectable. The very slight crossreaction with fragment $D$ can be neglected. The lower detection limit in the (latex agglutination) $D$ Dimer Test is $0.5 \mu \mathrm{g} / \mathrm{ml}$ fibrinogen-equivalents (normal range: $<0.5 \mu \mathrm{g} / \mathrm{ml}$ ). As is shown by the results of investigations using several reagent batches in differing D-Dimer concentration ranges, the sensitivity and reproducibility are not subject to batch-dependent variations.

A method-comparison between the D-Dimer Test and the Dimertest Latex showed good agreement, but the $D$-Dimer Test permits a more differentiated statement in the normal/pathological decision range. The $D$ Dimer Test can be carried out rapidly $(3 \mathrm{~min})$ and is characterized in particular by the simple and clear reading of latex agglutination, hence permitting reliable and unequivocal findings to be obtained even when used for the first time or by changing personnel in the night-shift or emergency laboratory.

Concentrations of fibrinogen-equivalents above $0.5 \mathrm{ng} / \mathrm{ml}$ are reliably detected with ELISA D-Dimer. Method-comparison showed good agreement with the D-Dimer Test and the Dimertest EIA in all concentration ranges. The high reliability of the ELISA D-Dimer method can be concluded from the within-run and day-to-day coefficients of variation of 1.6-2.1\% and 2.6-4.1\% respectively. As it is possible to use different supports, the method can be applied to differing instrumental systems, thereby permitting flexible use in practice.

Keywords:

Monoclonal antibodies - D-Dimer - latex agglutination test - ELISA - intravascular activation of coagulation 


\section{Einleitung}

\subsection{Allgemeines}

Zur Aufrechterhaltung der ungehinderten Blutzirkulation bei gleichzeitiger Gewährleistung der Blutstillungsfähigkeit müssen sich die Regulationsmechanismen des $\mathrm{Hä-}$ mostasesystems in einem ausgewogenen Verhältnis zueinander befinden (1).

Neben den Inhibitoren besitzt die Fibrinolyse im Bereich der plasmatischen Blutgerinnung wichtige regulative Funktionen. Bei Aktivierung der Hämostase polymerisiert Fibrinogen durch Einwirkung von Thrombin über verschiedene Zwischenstufen (Fibrinmonomere, lösliches Fibrin) bis zum quervernetzten Fibrin, das bei paralleler Aktivierung der Fibrinolyse in einem gegenläufigen Prozeß durch Plasmin wieder in lösliche Fragmente überführt werden kann (2). Es ist evident, daß eine Störung dieses Gleichgewichts - je nachdem in welche Richtung sie erfolgt - entweder zu Thrombophilie oder zu hämorrhagischen Diathesen führt (3). Ursachen für derartige Gleichgewichtsstörungen können einerseits hereditäre und erworbene Defizite bzw. Dysfunktionen einzelner Faktoren oder Inhibitoren, andererseits intravaskulär ablaufende Aktivierungsprozesse sein (4-6). Für die hämostaseologische Diagnostik bietet dieses Gleichgewicht einige interessante Ansatzpunkte zur Erkennung präthrombotischer bzw. thrombophiler Zustände oder beginnender intravaskulärer Aktivierungsprozesse. Geeignete Testmethoden könnten schon zu einem frühen Zeitpunkt prophylaktische und therapeutische Maßnahmen zur Verhinderung thromboembolischer Komplikationen und Verbrauchskoagulopathien ermöglichen.

Da Bildung und Abbau von Fibrin die zentralen Reaktionen dieses Gleichgewichtssystems darstellen, sollten durch die Bestimmung geeigneter Fibrinogen- und Fibrinderivate Informationen über das Gleichgewicht zu erhaiten sein (7). So kann bei ablaufenden Aktivierungsprozessen die Thrombinwirkung durch die Parameter Fibrinopeptid A und lösliche Fibrinmonomer-Komplexe nachgewiesen werden, während die Fibrinogenbzw. Fibrinspaltprodukte die Plasminwirkung belegen und damit Ausdruck einer sekundären Fibrinolyse sind $(8-10)$. Die diagnostische Aussage der Fibrin(ogen)spaltproduktbestimmung konnte bislang wegen der fehlenden Differenzierungsmöglichkeit zwischen Fibrinogen- und Fibrinfragmenten nicht voll ausgeschöpft werden. Die bisher gebräuchlichen Tests basieren auf polyklonalen Antikörpern gegen die Fibrinogenfragmente D und $E$ (13) oder den Agglutinationseigenschaften von fibrinogensensibilisierten Erythrozyten (Tanned Red Cells Hemagglutination Inhibition Immunoassay) (11) und Staphylococcenstämmen (12). Eine Differenzierung zwischen den Abbauprodukten des Fibrinogens einerseits und des Fibrins andererseits ist mit diesen Methoden nicht möglich, weil beide Spaltprodukttypen nahezu identische antigene Determinanten und damit gleichartiges Agglutinationsverhalten aufweisen. Da außerdem auch in hohem Maße Kreuzreaktion mit Fibrinogen auftritt, kann Citratplasma nicht als Probenmaterial eingesetzt werden. In einem besonderen Probenvorbereitungsschritt muß defibriniertes Serum gewonnen werden. Die korrekte Gewinnung dieses Serums ist zwar durch spezielle Abnahmesysteme einfacher und zuverlässiger geworden, stellt aber trotzdem im Routinebetrieb eine nicht zu unterschätzende Fehlermöglichkeit dar (13).

Inzwischen stehen immunologische Methoden mit monoklonalen Antikörpern zur Verfügung, die durch Immunisierung mit einem Fibrinfragment hergestellt wurden, dessen antigene Determinante nur in quervernetztem, stabilisiertem Fibrin und seinen Fragmenten auftritt. Dieses Fragment ist das D-Dimer $(14,15)$. Durch den Einsatz monoklonaler Antikörper zum spezifischen Nachweis der D-Dimere ergeben sich folgende Möglichkeiten:

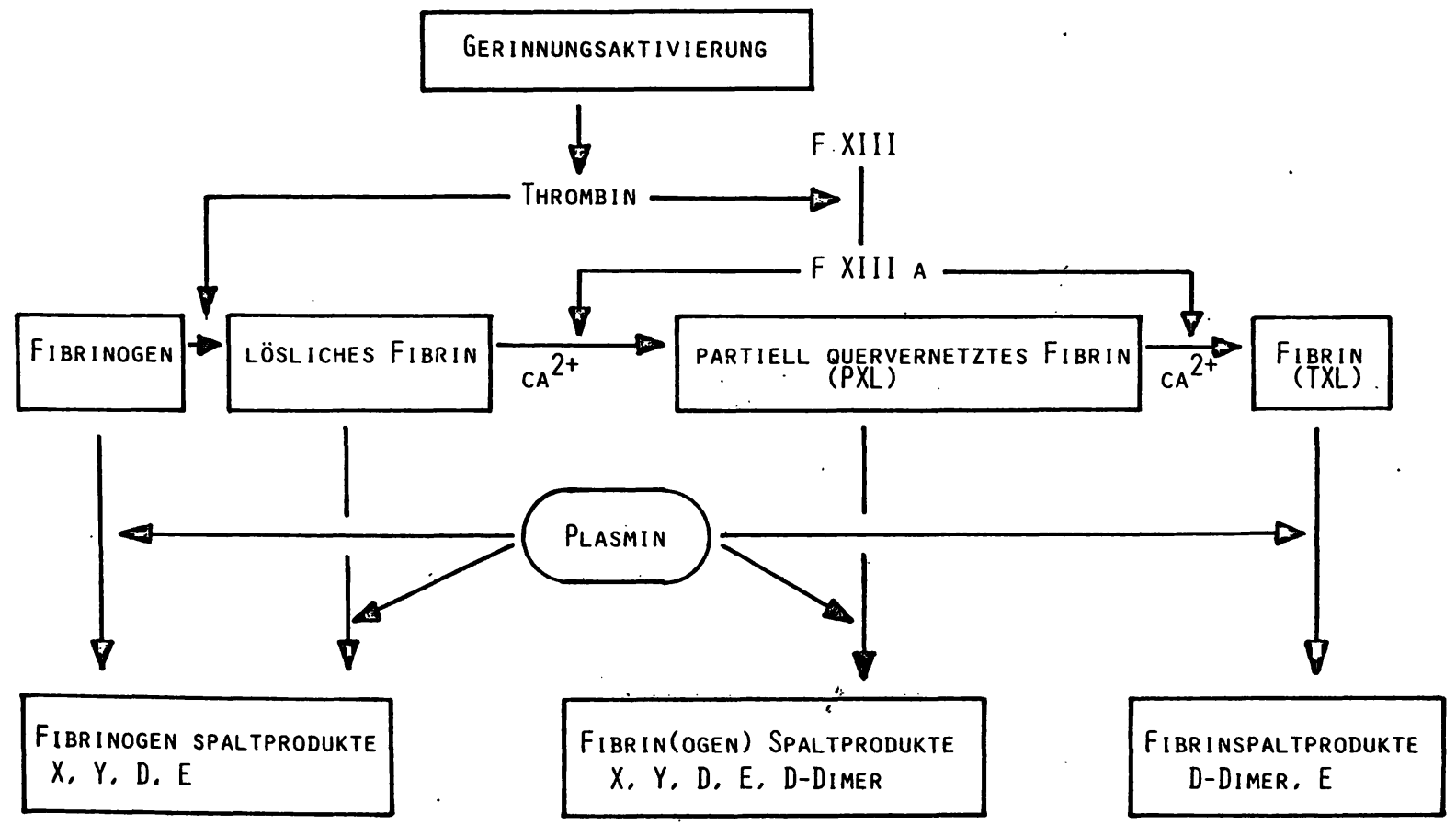

Aḅb. 1: Schematische Darstellung der Fibrinbildung und der aus den verschiedenen Zwischenstufen durch Einwirken von Plasmin. entstehenden Spaltprodukte [nach J. Gaffney (21)] 

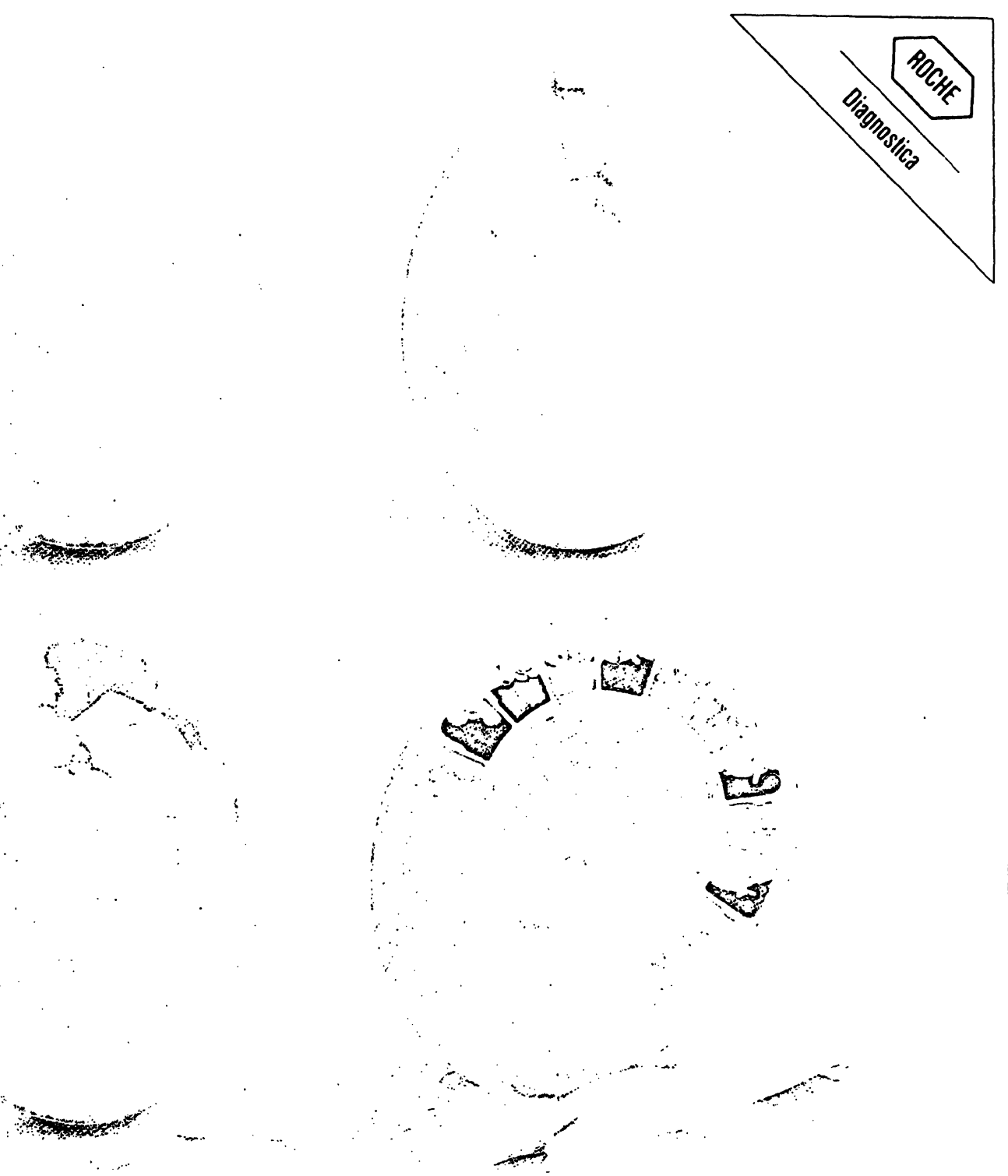

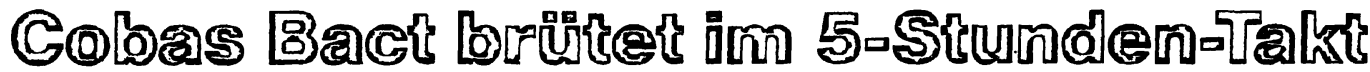

Cobas Bact ist ein automatisiertes System zur schnellen Empfindlichkeitsprüfung und Identifikation häufig auftretender Infektionserreger für das mikrobiologische Labor.

Empfindlichkeitsprüfungen sind schon nach 5 Stunden, die Identifizierung von Enterobacteriaceae bereits nach 4 Stunden durchgeführt und ausgewertet.

Darüber hinaus unterstreichen folgende Punkte eindrucksvoll die Leistungstähigkeit des Cobas Bact Systems:

\section{Empfindlichkeitsprüfung}

- Standardisierte, kinetische Wachstumsmessung

- Reproduzierbare Auswertung

- Zwischenergebnisse jederzeit als Extinktion der Wachstumskurven abrufbar

- Individuelle, aktuelle und flexible Antibiotika-Zusammenstellung für Antibiogramme
2. Identifizierung der Enterobacteriaceae

- Biochemische Reaktionen

- Biocode-Ausdruck zur Plausibilitätsprüfung

\section{EDV-Kompatibel}

- Integriertes Interface

Für weitere Informationen und Erprobungstermine stehen wir Ihnen gerne zur Verfügung.

Hoffmann-LaRoche AG - Diagnostica - 7889 Grenzach-Wyhlen - Tel. (07624) 141 


\section{Tabellen und}

Methoden

\section{zur medizinisch- bakteriologischen Laborpraxis}

Isolierung und Identifizierung pathogener Mikroorganismen sind die Voraussetzungen für Diagnose, Therapie, Verhütung von Infektionen und zur Infektionskontrolle.

In dem vorliegenden Buch werden die bisher in jedem qualifizierten mikrobiologischen Labor eingeführten kulturellen und biochemischen Verfahren beschrieben.

Die wichtigsten Daten von ca. 400 als Krankheitserreger geltenden oder aus differentialdiagnostischen Gründen im Bereich der Humanmedizin interessierenden Bakterienspezies sind in einem kompakten Abriß zusammengefaßt.

Der erste Teil des Buches informiert über Gewinnung, Transport und Verarbeitung von Untersuchungsmaterialien, der Hauptteil enthält sehr ausführlich kommentierte Tabellen zur Identifizierung der Mikroorganismen, und im Anschluß daran werden die im Text erwähnten Methoden unter Angabe von Bezúgsquellen für notwendige Hilfsmittel erläutert.

Das zum Gebrauch am Arbeitsplatz bestimmte Buch wendet sich an Mikrobiologen, Hygieniker, Pharmazeuten, medizinisch-technische Assistentinnen und alle diejenigen, die routinemäßig bakteriologische Untersuchungen durchführen oder sich im Praktikum auf diese Tätigkeit vorbereiten.

$-s<$

An Verlag Kirchheim, Kaiserstraße 41, 6500 Mainz

Ich bestelle gegen Rechnung ......... Expl. Bürger/Hussain:

Tabellen und Methoden zur med.-bakteriologischen Laborpraxis, zum Preis von DM 68,-

Name/Praxis:

Straße:

PLZ: Ort: Unterschrift:

Format $17 \times 24 \mathrm{~cm}$, 256 Seiten,

Abbildungen,

Tabellen, PVC-Einband, ISBN 3-87409-006-X, DM 68,-

Bezug über Verlag oder Fachbuchhandlung

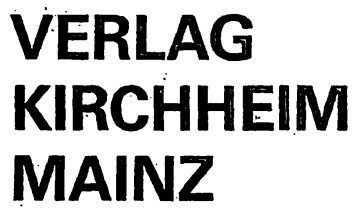

Datum: 
1. Citratplasma kann als Probenmaterial eingesetzt werden, da keine Kreuzreaktion mit Fibrinogen auftritt.

2. Durch den spezifischen Nachweis von Fibrinspaltprodukten kann die Lyse am Gerinnsel direkt nachgewiesen werden, ohne daß die systemische Fibrinogenolyse die Ergebnisse verfälscht.

\subsection{Biochemie}

Die Reaktionsfolgen zur Bildung von Fibrinogen- und Fibrinspaltprodukten sind in Abb. 1 schematisch dargestellt.

Aus Fibrinogen entsteht durch die thrombininduzierte Abspaltung der Fibrinopeptide A und B lösliches Fibrin (lösliche Fibrinmonomerkomplexe). Gleichzeitig wird Faktor XIII durch Thrombin aktiviert, der das lösliche Fibrin durch eine kovalente Bindung zwischen den $\gamma$-Ketten benachbarter Moleküle quervernetzt und in stabilisiertes, unlösliches Fibrin überführt. Dadurch entsteht um die Region der Quervernetzung eine neue antigene Determinante.

Bei der Fibrinolyse wird quervernetztes Fibrin in einem mehrstufigen Prozeß abgebaut, wobei die Verknüpfungsstellen erhalten bleiben. Als lösliche Endprodukte entstehen die Fragmente D-Dimer und D-Dimer-E (Abb. 2). Wird partiell quervernetztes Fibrin gespalten, entstehen zusätzlich zu den D-Dimeren die Fibrinogenspaltprodukte $X, Y, D$ und $E$. Das Mengenverhältnis hängt vom Grad der Quervernetzung ab. Vereinfacht stellt sich der Abbau von Fibrinogen bzw. Fibrin durch Plasmin, wie in Abb. 2 gezeigt, dar.

\subsection{Klinische Bedeutung}

Pathologisch erhöhte D-Dimer-Konzentrationen sind bei intravasaler Gerinnungsaktivierung mit sekundärer Fibrinolyse zu erwarten, d.h. bei Prozessen, die zu Thrombosen, disseminierter intravaskulärer Gerinnung mit Mikrothrombosierung und Verbrauchskoagulopathie und deren klinischen Begleiterscheinungen führen. Ebenso treten D-Dimere bei malignen Erkrankungen erhöht auf, bei denen lokal eine Fibrinbildung und Fibrinolyse stattfindet (z.B. Ovarialkarzinome, Lungenmetastasen). Außerdem führt eine therapeutische Thrombolyse durch den Fibrinabbau ebenfalls zu erhöhter D-Dimer-Konzentration.

Daraus ergeben sich die wichtigsten Indikationen für die D-Dimer-Bestimmung.

\section{Thrombose- und Emboliediagnostik}

Von Gaffney (16) wurde bei Patienten mit diagnostisch gesicherter tiefer Venenthrombose eine deutliche Erhöhung der D-Dimer-Konzentration nachgewiesen. Patienten mit Lungenembolie zeigten nochmals um ein mehrfaches höhere Werte. Diese Untersuchungen haben zu der Hypothese geführt, daß die D-Dimere eine Markerfunktion für thromboembolische Erkrankungen besitzen. Damit könnte die D-Dimer-Bestimmung die Möglichkeit eröffnen, Thrombosen mit einer nichtinvasiven Methode zu erkennen und darüber hinaus durch engmaschige Beobachtung der D-Dimer-Konzentration auftretende Lungenembolien zu diagnostizieren.

\section{Kontrolle der thrombolytischen Therapie}

Bei einer thrombolytischen Therapie kann mit den bisherigen Methoden keine Information darüber erhalten wer-

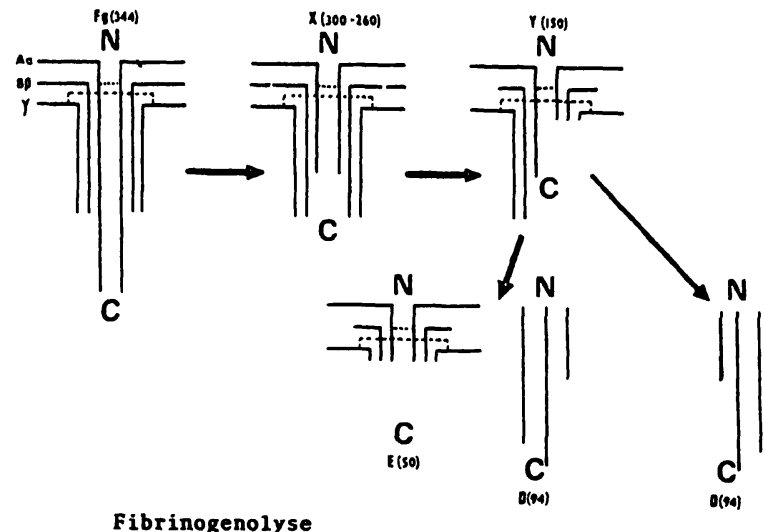

Fibrinogenolyse

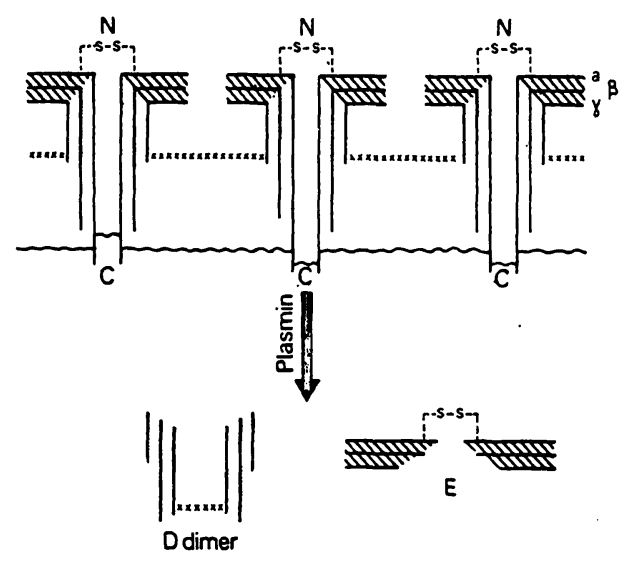

Fibrinolyse

Abb. 2: Fragmentierung von Fibrinogen und quervernetztem stabilisiertem Fibrin durch Plasmin [nach J. Gaffney (21)]

den, ob die Lyse tatsächlich am Thrombus angreift oder nur Fibrinogen abgebaut wird. Die Bestimmung der DDimer-Konzentration könnte diese Informationen erbringen. Aufgrund der Antikörperspezifität ist keine Beeinflussung der Resultate durch die systemische Fibrinogenolyse zu erwarten.

Diagnostik des präthrombotischen Zustandes, der Hyperkoagulabilität und Verbrauchskoagulopathie

\section{Ergänzende Tumordiagniostik}

Bei zahlreichen malignen Erkrankungen ist die Ausbreitung der Tumore mit lokaler Fibrinbildung und Fibrinauflösung im umgebenden Gewebe und im Tumor selbst verknüpft. Die bei dieser Fibrinolyse freigesetzten D-Dimere können, wie Graeff et al. (17) zeigten, als Tumormarker eingesetzt werden.

Seit kurzem sind Tests zur Bestimmung der D-Dimere auch kommerziell erhältlich. Entsprechend den unterschiedlichen Anforderungen der Diagnostik, nämlich quantitative Bestimmung der D-Dimer-Konzentrationen zur Verlaufsbeobachtung einerseits und die sofortige Ja/ Nein-Entscheidung in Akutfällen andererseits, wurde eine quantitative Methode und ein qualitativer Schnelltest hinsichtlich ihrer diagnostischen Validität untersucht. 


\section{Material und Methoden}

\subsection{Patienten}

Zur Beurteilung der Testvalidität wurden Plasmen und Seren von vier Patientengruppen herangezogen. Bei den vier Untersuchungskollektiven war aufgrund der klinischen Situation intravasale Aktivierung des Gerinnungssystems mit sekundärer Fibrinolyse zu erwarten. In den untersuchten Kollektiven befanden sich Patienten mit Lungenembolien (25), Lungenmetastasen (50) und Ovarialkarzinomen (27), Verbrauchskoagulopathie (24) sowie eine Kontrollgruppe aus gesunden männlichen und weiblichen Probanden (60) und bei einigen Untersuchungen eine Gruppe (24) stationär behandelter Patienten, die aber keine Anzeichen einer Gerinnungsstörung aufwiesen.

\subsection{Methoden}

Als quantitative Bestimmungsmethode diente der enzymimmunologische Test „ELISA D-Dimer”, Boehringer Mannheim, und als bed side test der Latex-Agglutinationstest „D-Dimer-Test“, Boehringer Mannheim.

\section{ELISA D-Dimer (Boehringer Mannheim)}

Monoklonale Antikörper $\left[F\left(a b^{\prime}\right)_{2}\right.$-Fragmente, Maus Ig GI] gegen D-Dimer werden im Überschuß an geeignete Trägermaterialien fixiert ( $16 \mathrm{~h}$ bei Raumtemperatur). Zum Entfernen nichtgebundener Antikörper wird das Trägermaterial $3 \mathrm{mal}$ mit einer speziellen Waschlösung $(0,9 \%$ $\mathrm{NaCl}, 0,1 \%$ Tween 20) gewaschen. Anschließend werden je $200 \mu l \mathrm{D}$-Dimer-Standard (Verdünnungen von 50$1 \mathrm{ng} / \mathrm{ml}$ ) oder die vorverdünnte Plasmaprobe aufgetragen und $1 \mathrm{~h}$ bei Raumtemperatur inkubiert. Nach einem weiteren Waschschritt folgt die zweite Inkubation mit $200 \mu \mathrm{l}$ einer Lösung von polyklonalen peroxidase-markierten FDP-D-Antikörpern. Im Anschluß an einen Waschschritt wird die Farbreaktion durch Zugabe von $200 \mu \mathrm{l}$ Substratlösung (ortho-Phenylendiamin, $\mathrm{H}_{2} \mathrm{O}_{2}$ ) gestartet und die Reaktion nach drei Minuten mit $50 \mu \mathrm{l}$ $3 \mathrm{M} \mathrm{H}_{2} \mathrm{SO}_{4}$ gestoppt. Die Absorption wird bei $492 \mathrm{~nm}$ gemessen und das Ergebnis anhand der Bezugskurve aus den Standardverdünnungen ermittelt.

\section{D-Dimer-Test (Boehringer Mannheim)}

D-Dimer-Test ist ein direkter Latexagglutinationstest, bei dem Latexpartikel einheitlicher Größe mit Antikörpern (monoklonal Maus lg GI) gegen D-Dimer beladen sind. Die Probe wird unverdünnt oder zur halbquantitativen Bestimmung als Verdünnungsreihe auf einer Testplatte mit der Latexsuspension gemischt. Bei Anwesenheit von D-Dimeren in der Probe kommt es nach 2 min zu einer deutlich sichtbaren Agglutination. Zur sicheren Befundung enthält die Testkombination ein Kontrollplasma mit einer D-Dimer-Konzentration im pathologischen Bereich.

Dimertest EIA und Dimertest Latex (Mabco, Brisbane, Australien, Vertrieb in der Bundesrepublik durch Travenol; Bereich Merz \& Dade) wurden entsprechend den Angaben des Herstellers durchgeführt.

\section{D-Dimer-Standard}

Zur Herstellung des D-Dimer-Standards wird gereinigtes Fibrinogen, dessen Konzentration gravimetrisch, immunologisch und nach Clauss bestimmt wurde, mit Thrombin in Gegenwart von F XIII a, Ca-lonen und Plasminogen bei $37^{\circ} \mathrm{C}$ zur Gerinnung gebracht und $2 \mathrm{~h}$ inkubiert.

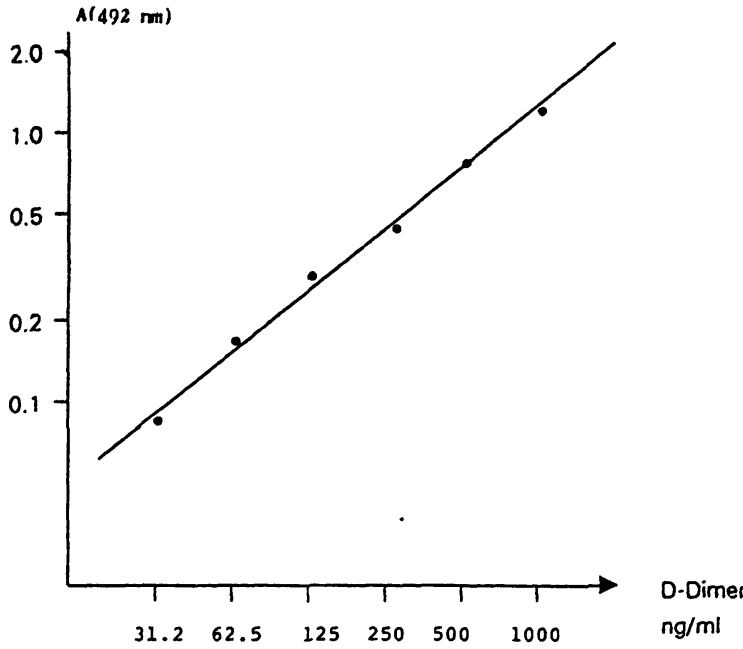

Abb. 3: Typische Bezugskurve von ELISA D-Dimer auf der Basis des D-Dimer-Standards (linearer Bereich: $10-1000 \mathrm{ng} / \mathrm{ml} \mathrm{Fi-}$ brinogenäquivalent)

Danach erfolgt die Zugabe von t-PA. Die Fibrinolyse wird nach $24 \mathrm{~h}$ durch Zugabe von Aprotinin gestoppt. Unter den genannten Reaktionsbedingungen ist sämtliches Fibrinogen in die Fibrinspaltprodukte D-Dimer und DDimer-E überführt worden.

Die Konzentration des Standards wird in $\mathrm{ng} / \mathrm{ml}$ Fibrinogenäquivalente der zur Standardherstellung verwendeten Fibrinogenmenge angegeben. Die D-Dimer-Konzentration entspricht etwa $50 \%$ dieses Wertes. Das Verfahren gestattet eine nahezu chargenunabhängige Produktion des Standards.

\section{Fibrinogen- und Fibrin-Spaltprodukte}

Für die Untersuchungen zur Kreuzreaktion der D-DimerTests wurden verschiedene Fibrin- und Fibrinogenderivate in den entsprechenden Tests eingesetzt. Gereinigtes Fibrinogen wurde nach der Methode von Blombäck et al. (18) hergestellt. Frühe (X, Y), späte (D, E)-Fibrinogenspaltprodukte wurden, wie bereits in (13) beschrieben, präpariert. Gereinigte Fragmente $D$ und $E$ wurden durch PEVIKON-Gelelektrophorese nach Marder (19) aus der Lösung der späten Fibrinogenspaltprodukte isoliert. Für frühe und späte Fibrinspaltprodukte wurde gereinigtes Fibrinogen bei $37^{\circ} \mathrm{C}$ in Gegenwart von $\mathrm{Ca}$-lonen und FXIII a zur Gerinnung gebracht und $2 \mathrm{~h}$ inkubiert. Die Lyse wurde durch Zugabe von $2000 \mathrm{ng}$ t-PA (aus einer Melanom-Zellinie) gestartet. Durch Zugabe von 50 TIU Aprotinin nach 10, 20 bzw. 30 min Inkubation erhält man frühe Fibrinspaltprodukte, nach $24 \mathrm{~h}$ Inkubation die späten Fibrinspaltprodukte (20). Zur Gewinnung von hochgereinigtem D-Dimer wird die Lösung der späten Fibrinspaltprodukte über lonenaustauschchromatographie und Gelfiltration gereinigt (20).

\section{Ergebnisse}

\subsection{EL.ISA D-Dimer}

\subsubsection{Linearität und Empfindlichkeit}

Eine typische Bezugskurve auf der Basis des in der Packung enthaltenen D-Dimer-Standards ist in Abb. 3 dargestellt. Bei einer Plasmaverdünnung von 1:20 ergibt 


\section{Bei Licht besehen (1)}

Am Anfang war das Licht . . .

Mit dem Licht beginnt die geordnete und lebendige Welt. Das Licht hat Forscher und Wissenschaftler schon immer fasziniert. Ihre Entdeckungen und Entwicklungen haben unser Leben revolutioniert. Die Steuerung und Nutzbarmachung von Licht stellt für jede Generation eine Herausforderung an ihr wissenschaftlich-innovatives Denken dar.

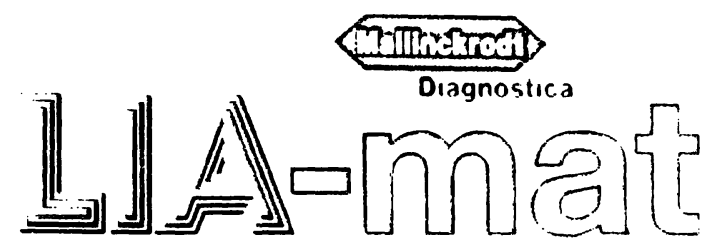

Lumineszenz-Immuno-Assays

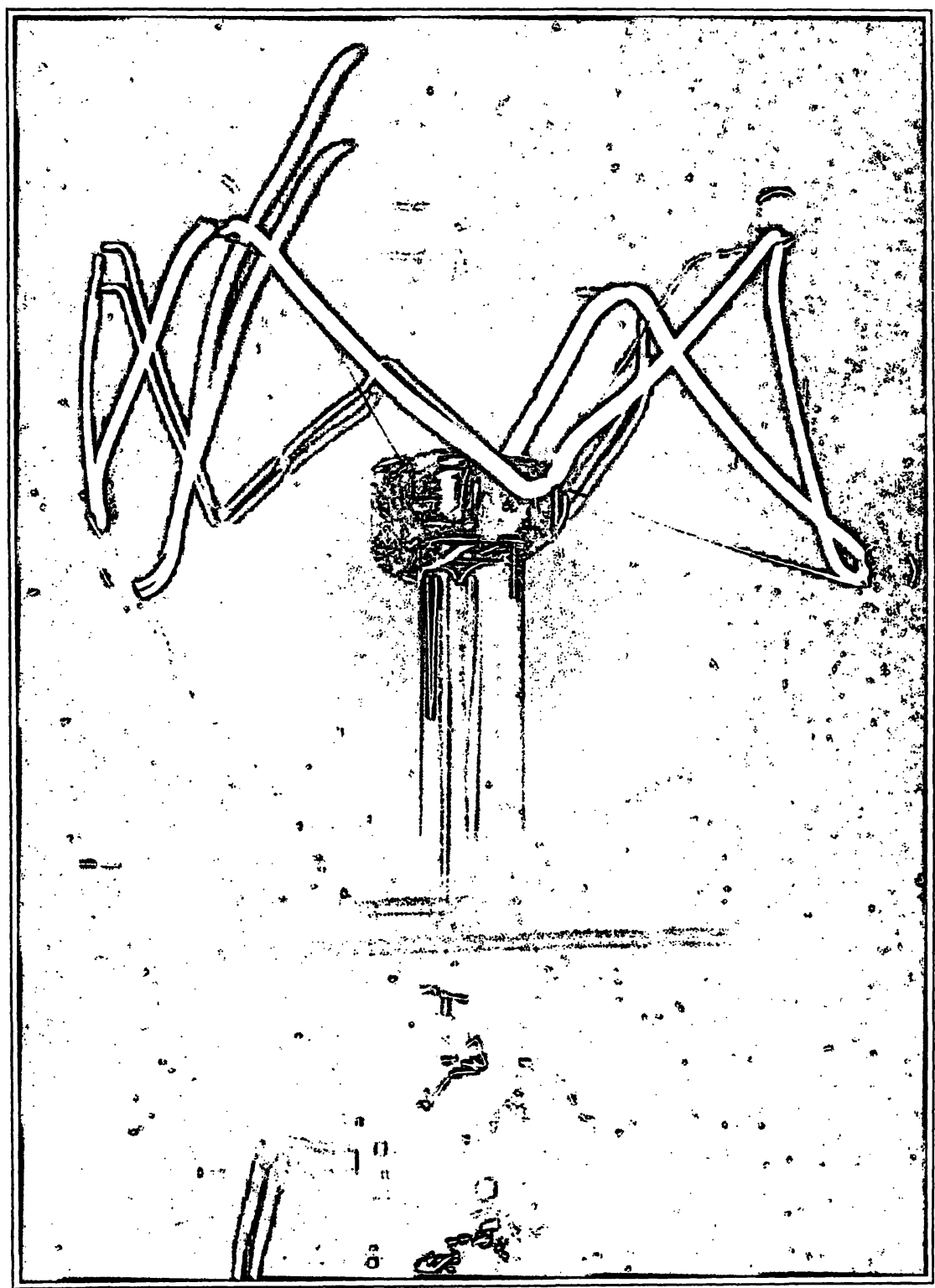

Poster auf Antrage kostenlos erhaltlich (Stıchwort: LIA-mat 1)

\section{Thomas Alva Edison}

stellt die erste technisch verwertbare Glühlampe vor.

Der Weg in eine helle Zukunft beginnt.
1987 Mallinckrodt Diagnostica stellt LIA-mat" Lumineszenz-ImmunoAssays vor. Chemisch erzeugte Lichtsignale eröffnen neue Wege und Perspektiven in der Labor-Diagnostik. 


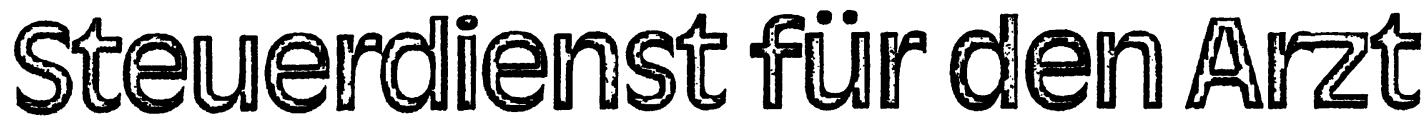

Die für den Arzt einschlägigen Urteile finden Sie - nach Stichworten geordnet - in dem Loseblattwerk von Obersteuerrat Robert Linden.

Das Werk enthält u. a. die statistischen Kostensätze der Ärzte aller Fachrichtungen sowie Testbögen, die eine genaue Kostenanalyse der Praxis ermöglichen. Der Rationalisierung Ihrer Praxis dient das ausführliche „ABC der abzugsfähigen Ausgaben bei der Einkommensteuer".

\section{Hand aufs Herz}

* Verschenken Sie nicht auch Jahr für Jahr viel Geld an das Finanzamt?

* Nehmen Sie alle legalen Steuerminderungsmöglichkeiten in Anspruch?

* Stellen Sie rechtzeitig die notwendigen Anträge?

* Haben Sie Zeit und Gelegenheit, sich über Ihre berufsspezifischen Steuerfragen in den Steuerfachzeitschriften zu orientieren?

* Verlassen Sie sich ganz auf Ihren Berater?

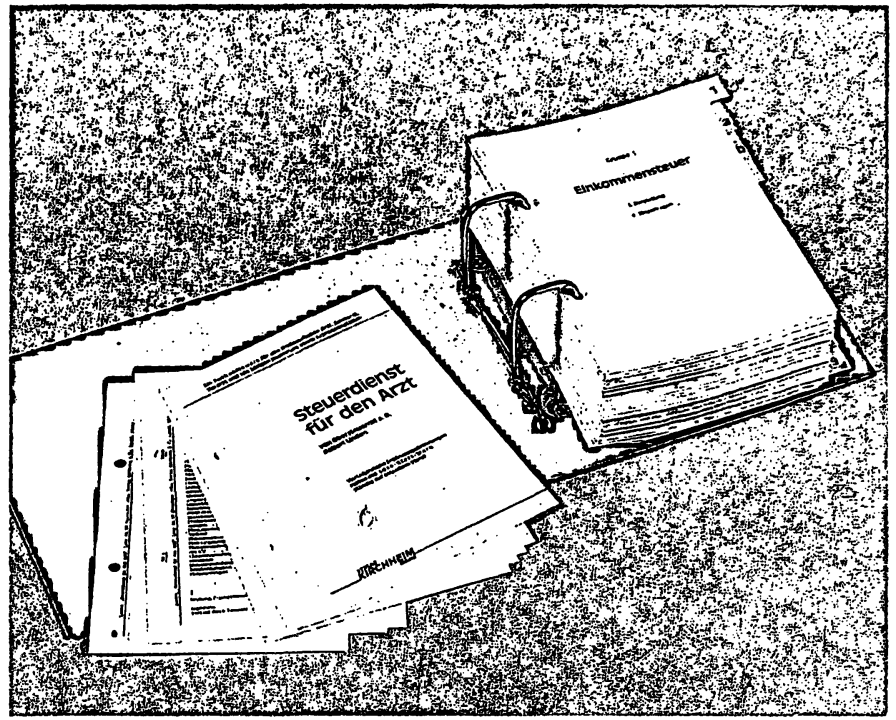

* Haben Sie schon einmal einen Praxiskostentest gemacht?

* Wissen Sie, ob Sie mehr oder weniger als Ihre vergleichbaren Kollegen verdienen?

\section{VERLAG \\ KIRCHHEIM Postfach 2524,6500 Mainz 1 MAINZ}

Hiermit bestelle ich ein Grundwerk „Steuerdienst für den Arzt" zum Preis von 79,80 DM und die künftig vierteljährlich erscheinenden Ergänzungslieferungen zum Seitenpreis von ,- 37 DM.

Sie garantieren mir, daß ich diese Bestellung binnen einer Frist von einer Woche schriftlich widerrufen kann. Der Widerruf ist an den Verlag Kirchheim, Postfach 25 24, 6500 Mainz, zu richten. Zur Wahrung der Frist genügt die rechtzeitige Absendung des Widerrufs.
Anschrift:

Name:

Straße:

PLZ/Ort: 
Tab. 1: Präzision in der Serie und von Tag zu Tag von ELISA-D Dimer bei Proben mit verschiedenen D-Dimer-Konzentrationen $(V K=$ Variationskoeffizient)

\begin{tabular}{|c|c|c|c|c|}
\hline \multirow[t]{2}{*}{ Probe } & \multicolumn{2}{|c|}{$\begin{array}{l}\text { Präzision } \\
\text { in der Serie } \\
N=10\end{array}$} & \multicolumn{2}{|c|}{$\begin{array}{l}\text { Präzision } \\
\text { von Tag zu Tag } \\
N=12\end{array}$} \\
\hline & $\begin{array}{l}\text { mittlere } \\
\text { D-Dimer- } \\
\text { Konzen- } \\
\text { tration } \\
\text { (ng/ml) }\end{array}$ & VK (\%) & $\begin{array}{l}\text { mittlere } \\
\text { D-Dimer- } \\
\text { Konzen- } \\
\text { tration } \\
\text { (ng/ml) }\end{array}$ & VK $(\%)$ \\
\hline $\begin{array}{l}\text { A } \\
B \\
C \\
D\end{array}$ & $\begin{array}{l}280,4 \\
393,1 \\
498,2 \\
653,2\end{array}$ & $\begin{array}{l}2,1 \\
2,1 \\
1,8 \\
1,6\end{array}$ & $\begin{array}{l}290,7 \\
385,2 \\
490,3 \\
698,2\end{array}$ & $\begin{array}{l}2,8 \\
2,6 \\
4,1 \\
3,3\end{array}$ \\
\hline
\end{tabular}

Tab. 2: Wiederfindung der D-Dimer-Konzentration mit ELISAD-Dimer in Citratplasma mit künstlich zugesetztem D-Dimer

\begin{tabular}{llcr}
\hline $\begin{array}{l}\text { Zugesetzte } \\
\text { D-D Konzen- } \\
\text { tration } \\
\text { (ng/ml Fibrino- } \\
\text { genäquivalent) }\end{array}$ & $\begin{array}{l}\text { theoretische } \\
\text { Konzen- } \\
\text { tration } \\
\text { (ng/ml) }\end{array}$ & $\begin{array}{l}\text { gemessene \% Wieder- } \\
\text { Konzen- } \\
\text { tration }\end{array}$ & findung \\
\hline Plasma 1 & - & 60 & \\
\hline 60 & 120 & 110 & 92 \\
250 & 310 & 300 & 97 \\
500 & 560 & 570 & 102 \\
1500 & 1560 & 1500 & 99 \\
\hline Plasma 2 & - & 100 & \\
\hline 60 & 160 & 150 & 94 \\
250 & 350 & 340 & 97 \\
500 & 600 & 600 & 100 \\
1500 & 1600 & 1700 & 106 \\
\hline Plasma 3 & - & 170 & \\
\hline 60 & 230 & 230 & 100 \\
250 & 420 & 420 & 100 \\
500 & 670 & 650 & 97 \\
1500 & 1670 & 1600 & 96 \\
\hline
\end{tabular}

Tab. 3: Kreuzreaktion der $F\left(a b^{\prime}\right)_{2}$-Fragmente im ELISA-D-Dimer mit Fibrinogen und verschiedenen Fibrinogen - bzw. Fibrinspaltprodukten

Produkt

Kreuzreaktion

(\%)

\begin{tabular}{|c|c|}
\hline $\begin{array}{l}\text { Fibrinogen (in Citratplasma) } \\
\text { frühe FDP (Fibrinogen) } \\
\text { späte FDP (Fibrinogen) } \\
\text { FDP-E (Fibrinogen) } \\
\text { FDP-D (Fibrinogen) } \\
\text { FDP (XL-Fragmente, Fibrin) } \\
\text { D-Dimer }\end{array}$ & $\begin{array}{r}0,001 \\
0,005 \\
4,000 \\
<0,001 \\
10,000 \\
100,000 \\
100,000\end{array}$ \\
\hline
\end{tabular}

sich ein linearer Meßbereich von $10-1000 \mathrm{ng} / \mathrm{ml}$. Höhere D-Dimer-Konzentrationen können durch entsprechend höhere Probenvorverdünnung erfaßt werden.

\subsubsection{Präzision}

Zur Ermittlung der Präzision in der Serie und von Tag zu Tag wurde die D-Dimer-Konzentration in vier verschiedenen Plasmaproben bestimmt. Für die Präzision in der Serie wurde ein Variationskoeffizient von 1,6-2,1\% und von Tag zu Tag ein Variationskoeffizient von $2,6-4,1 \%$ ermittelt (Tab. 1).

\subsubsection{Richtigkeit}

Plasmen von Normalprobanden, deren D-Dimer-Konzentrationen bekannt sind, wurden mit definierten, unterschiedlichen Mengen von gereinigtem Human-D-Dimer versetzt. Zur Ermittlung der Wiederfindungsrate wurden die Konzentrationen in diesen Proben bestimmt. Die Ergebnisse sind in Tabelle 2 zusammengestellt. Es wird eine Wiederfindung von $92-106 \%$ erhalten.

\subsubsection{Kreuzreaktion mit anderen Fibrinogen- und Fibrinderivaten}

Von besonderer Bedeutung für die Beurteilung immunologischer Testmethoden sind mögliche Kreuzreaktionen der Antikörper. Zur Überprüfung wurden Lösungen von Fibrinogen, Fibrinogen- und Fibrinspaltprodukten im Test eingesetzt. In Tab. 3 sind die beobachteten Kreuzreaktionen im Vergleich zur Reaktion mit gereinigtem D-Dimer $(=100 \%)$ angegeben.

Wie aufgrund der unterschiedlichen antigenen Determinanten von Fibrinogen und seinen Spaltprodukten gegenüber D-Dimer zu erwarten, ist die Kreuzreaktion mit den Fibrinogenspaltprodukten $X, Y$ und $E$ vernachlässigbar. Nur Fibrinogenfragment $D$ zeigt eine mäßige Reaktion im Test.

\subsection{D-Dimer-Test}

\subsubsection{Empindlichkeit und Reaktion mit Fibrinogen- und Fibrinderivaten}

Tabelle 4 faßt die Ergebnisse zur Überprüfung der Nachweisgrenze und der Kreuzreaktion mit Fibrinogenderivaten zusammen. Dazu wurden Lösungen der verschiedenen Fibrinogen- und Fibrinderivate sukzessive verdünnt und im Test ohne weitere Probenvorverdünnung eingesetzt.

Die Nachweisgrenze ist die Konzentration, bei der gerade noch eine Agglutination erhalten wird. Mit Fibrinogen und Fibrinogenspaltprodukten, mit Ausnahme von FDP. D, wurden keine Kreuzreaktionen beobachtet.

Tab. 4: Kreuzreaktion des Antikörpers im D-Dimer-Test mit Fibrinogen- und Fibrinderivaten. Die entsprechenden Proben wurden unverdünnt im Test eingesetzt. $(+)=$ Agglutination, $(+++)$ sehr starke Agglutination, $(-)=$ keine Agglutination, $( \pm)$ Grenzbereich

\begin{tabular}{|c|c|c|c|c|c|c|c|c|}
\hline $\begin{array}{l}\text { Fibrinogenäquivalent } \mu \mathrm{g} / \mathrm{ml} \\
\text { Produkt }\end{array}$ & 1000 & 100 & 10 & 5 & 2 & 1 & 0,5 & 0 \\
\hline $\begin{array}{l}\text { Fibrinogen } \\
\text { Frühe Fibrinogenspaltprodukte } \\
\text { Späte Fibrinogenspaltprodukte } \\
\text { FDP-D (Fibrinogen) } \\
\text { FDP-E (Fibrinogen) } \\
\text { Frühe Fibrinspaltprodukte } \\
\text { Späte Fibrinspaltprodukte } \\
\text { D-Dimer }\end{array}$ & $\begin{array}{l}- \\
\pm \\
\pm \\
\bar{t} \\
+t \\
+t\end{array}$ & $\begin{array}{l}- \\
\pm \\
\pm \\
\bar{t}++ \\
+++ \\
+++\end{array}$ & $\begin{array}{l}- \\
- \\
- \\
\overline{t+}+ \\
+++ \\
+++\end{array}$ & $\begin{array}{l}- \\
- \\
- \\
- \\
++ \\
++ \\
++\end{array}$ & $\begin{array}{l}- \\
- \\
- \\
- \\
++ \\
++ \\
++\end{array}$ & $\begin{array}{l}- \\
- \\
- \\
- \\
+ \\
+ \\
+\end{array}$ & $\begin{array}{l}- \\
- \\
- \\
\overline{ \pm} \\
\pm \\
\pm\end{array}$ & $\begin{array}{l}- \\
- \\
- \\
- \\
- \\
- \\
-\end{array}$ \\
\hline
\end{tabular}


Tab. 5: Wiederfindung der D.Dimer-Konzentration mit verschiedenen Chargen D.Dimer-Test in aufgestockten Normalplasmen

\begin{tabular}{|c|c|c|c|c|c|}
\hline \multirow[t]{2}{*}{$\begin{array}{l}\text { D-Dimer-Konzentration } \\
\text { vor Aufstockung }\end{array}$} & \multirow[t]{2}{*}{ Bestimmung } & \multirow{2}{*}{$\begin{array}{l}\text { theoretische } \\
\text { D-Dimer-Konzentration } \\
\text { ( } \mu \mathrm{g} / \mathrm{ml} \text { Fibrinogenäquivalent) }\end{array}$} & \multicolumn{3}{|c|}{$\begin{array}{l}\text { gemessene D-Dimer-Konzentration } \\
(\mu \mathrm{g} / \mathrm{ml}) \text { Fibrinogenäquivalent }\end{array}$} \\
\hline & & & Ch. 11 & Ch. 12 & Ch. 13 \\
\hline Plasma $1<0,5$ & $\begin{array}{l}\text { A } \\
\text { B } \\
\text { C } \\
\text { D }\end{array}$ & $\begin{array}{l}1^{1-2} \\
20 \\
100\end{array}$ & $\begin{array}{r}1-2 \\
4-8 \\
20-40 \\
80-160\end{array}$ & $\begin{array}{r}1-2 \\
4-8 \\
20-40 \\
80-160\end{array}$ & $\begin{array}{r}1-2 \\
4-8 \\
20-40 \\
80-160\end{array}$ \\
\hline Plasma $2<0,5$ & $\begin{array}{l}A \\
B \\
C \\
D\end{array}$ & $\begin{array}{l}1^{-2} \\
20 \\
100\end{array}$ & $\begin{array}{r}1-2 \\
4-8 \\
20-40 \\
80-160\end{array}$ & $\begin{array}{r}1-2 \\
4-8 \\
20-40 \\
80-160\end{array}$ & $\begin{array}{r}1-2 \\
4-8 \\
20-40 \\
80-160\end{array}$ \\
\hline Plasma $3<0,5$ & $\begin{array}{l}\text { A } \\
B \\
C \\
D\end{array}$ & $\begin{array}{l}1^{-2} \\
.20 \\
100\end{array}$ & $\begin{array}{r}1-2 \\
4-8 \\
20-40 \\
80-160\end{array}$ & $\begin{array}{r}1-2 \\
4-8 \\
20-40 \\
80-160\end{array}$ & $\begin{array}{r}1-2 \\
4-8 \\
20-40 \\
80-160\end{array}$ \\
\hline
\end{tabular}

\subsubsection{Präzision und Wiederfindung}

Analog zU ELISA D-Dimer wurde mit D-Dimer-Test die Wiederfindung der D-Dimer-Konzentration in aufgestockten Plasmen untersucht. Zur semiquantitativen Bestimmung der D-Dimer-Konzentration wurde der D-Dimer-Test über die Verdünnungsreihe der Proben durchgeführt. Mit den verschiedenen Reagenzchargen konnte eine sehr gute Wiederfindung erhalten werden. Darüber hinaus weist die Methode eine zuverlässige, chargenunabhängig reproduzierbare Empfindlichkeit auf (Tab. 5). Die gefundenen Konzentrationsbereiche ergeben sich aus den Verdünnungsstufen der semiquantitativen Auswertung.

Zur Ermittlung der Präzision wurden vier Plasmaproben mit verschiedenen $D$-Dimer-Konzentrationen eingesetzt und in Serie $(N=15)$ und von Tag zu Tag $(N=20)$ getestet. Sowohl in der Serie als auch von Tag zu Tag

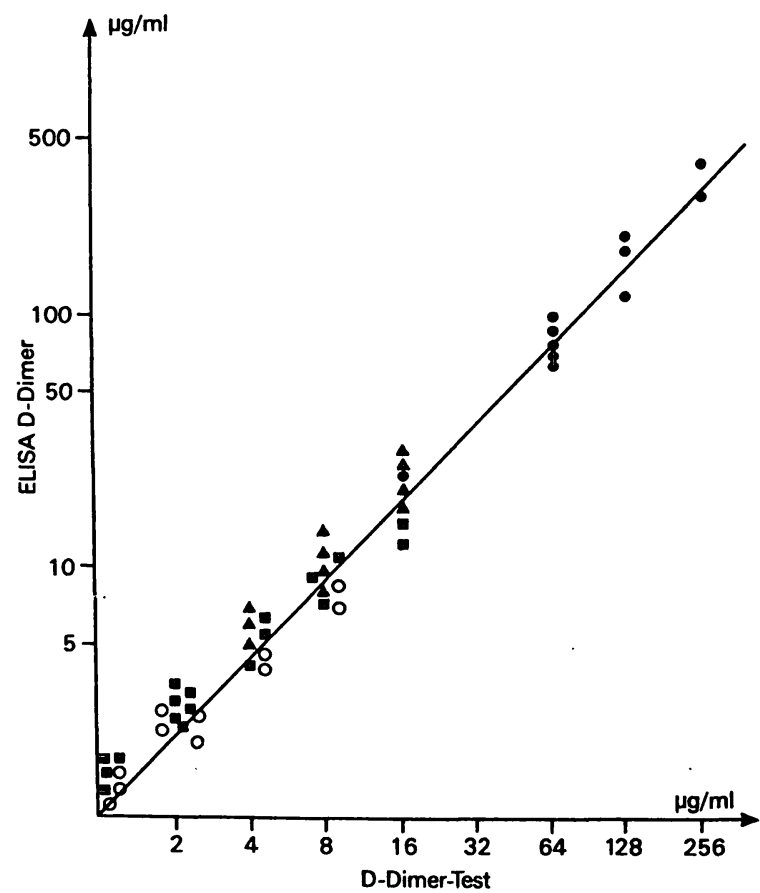

Abb. 4: Methodenvergleich ELISA D-Dimer und D-Dimer-Test: Verbrauchskoagulopathie (0), Lungenembolien (A) Ovarialkarzinom (ם), Lungenmetastasen (O) wurden keine Unterschiede im Agglutinationsverhalten gefunden.

\subsection{Methodenvergleich}

ELISA D-Dimer und D-Dimer-Test wurden sowohl untereinander als auch mit vergleichbaren Reagenzien anderer Hersteller verglichen. Zum Methodenvergleich wurden Dimertest EIA und Dimertest Latex der Firma Mabco eingesetzt.

\subsubsection{ELISA D-Dimer - D-Dimer-Test}

Mit beiden Methoden wurde die D-Dimer-Konzentration in Plasmen von Normalprobanden und der vier Patientengruppen bestimmt. Mit D-Dimer-Test wurde die Bestimmung semiquantitativ durchgeführt. Abb. 4 zeigt die gute Korrelation von ELISA D-Dimer und D-Dimer-Test bei erhöhten D-Dimer-Konzentrationen. Die Ergebnisse der Plasmen der Normalprobanden sind der besseren Übersicht wegen in der Abb. 5 zusammengefaßt. Auch hier zeigt sich die hervorragende Übereinstimmung der beiden Tests.

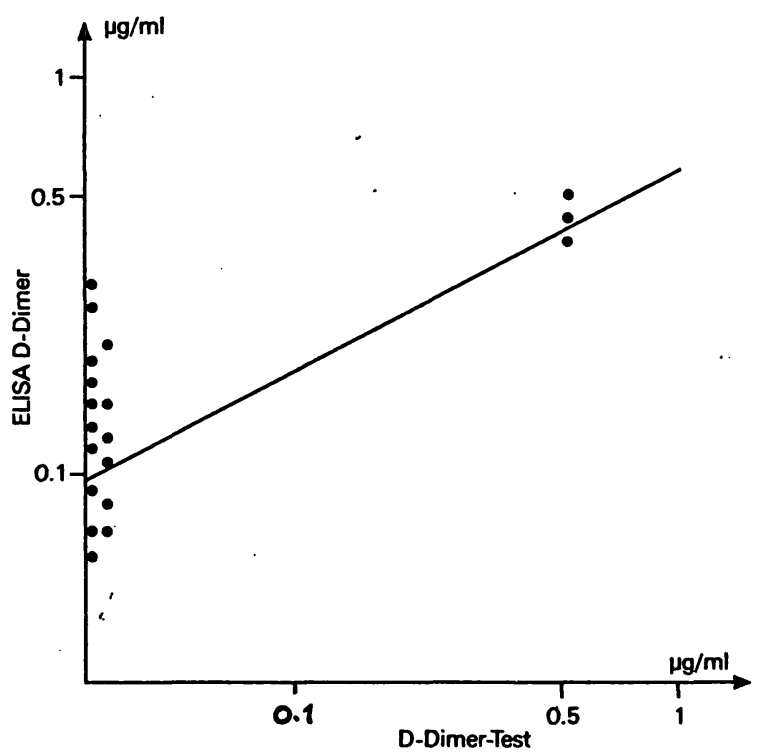

Abb. 5: Methodenvergleich ELISA D-Dimer und D-Dimer-Test . bei Normalprobanden 


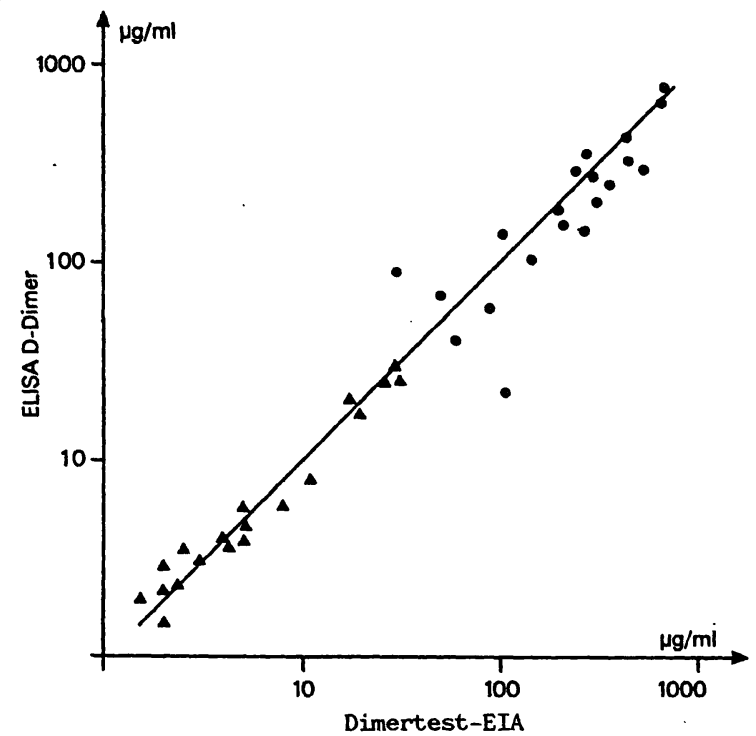

Abb. 6: Methodenvergleich ELISA D-Dimer und Dimertest EIA Verbrauchskoagulopathie (๑), Lungenembolie (A) (Konzentrationsangaben in Fibrinogen äquivalent)

\subsubsection{ELISA D-Dimer - Dimertest EIA}

Beim Methodenvergleich mit anderen Herstellern wurden ELISA-D-Dimer (Boehringer Mannheim) mit Dimertest EIA (Mabco) und D-Dimer-Test (Boehringer Mannheim) mit Dimertest Latex (Mabco) verglichen. Abb. 6 zeigt die Ergebnisse beim Vergleich der ELISA-Tests in Plasmen von Patienten mit Lungenembolien und Verbrauchskoagulopathie.

Beim Vergleich der absoluten Konzentrationen in $\mu \mathrm{g} / \mathrm{ml}$ ist zu beachten, daß beim Dimertest EIA (Mabco) das Ergebnis in $\mu \mathrm{g} / \mathrm{ml} \mathrm{D}$-Dimere angegeben wird, beim ELISA D-Dimer (Boehringer Mannheim) in $\mu \mathrm{g} / \mathrm{ml} \mathrm{Fibri-}$ nogenäquivalent. Zum direkten Vergleich müssen die Werte der mit dem Dimertest EIA erhaltenen D-DimerKonzentrationen durch Multiplikation mit dem Faktor 2 in Fibrinogenäquivalent umgewandelt werden.

Tab. 6: Methodenvergleich D-Dimer-Test und Dimertest Latex mit Plasmaproben von Normalprobanden

\begin{tabular}{lrll}
\hline $\begin{array}{l}\text { D-Dimer-Test (Boehringer) } \\
\mu g / m \text { Fibrinogenäquivalent } \\
\text { Dimertest Latex (Mabco) } \\
\mu \mathrm{g} / \mathrm{ml} \text { Fibrinogenäquivalent }\end{array}$ & $<0,5$ & $0,5-1$ & $1-2$ \\
\hline$<0,4$ & & & \\
$0,4-0,8$ & 52 & 0 & 0 \\
$0,8-1,6$ & 2 & 2 & 2 \\
\hline
\end{tabular}

\subsubsection{D-Dimer-Test - Dimertest Latex}

Es wurden Plasmen von Normalprobanden und von $\mathrm{Pa}$ tienten mit Verbrauchskoagulopathie eingesetzt. Beide Tests wurden semiquantitativ durchgeführt und die $\mathrm{Er}$ gebnisse in Tab. 6 bzw. Tab. 7 gegenübergestellt. Die mit dem D-Dimer-Test erhaltenen Ergebnisse weisen auf eine bessere Abstufung im Grenzbereich normal-pathologisch hin. Diese Aussage sollte durch Untersuchungen an gröBeren Patientenkollektiven erhärtet werden. Die unterschiedlichen Konzentrationsbereiche ergeben sich aus den jeweiligen Nachweisgrenzen der Methoden.

Beide Latex-Tests wurden auf ihre Spezifität und Empfindlichkeit geprüft. Dazu wurden Proben mit bekannten Konzentrationen der verschiedenen Fibrinogen- und $\mathrm{Fi}$ brinderivate sukzessive verdünnt in den Test eingesetzt und das Ergebnis qualitativ ausgewertet. Der D-DimerTest weist geringe Konzentrationen zuverlässiger nach, die Kreuzreaktion mit Fibrinogenderivaten ist geringer, wobei besonders die Reaktion des Dimertest Latex mit hohen Konzentrationen an späten Fibrinogenspaltprodukten auffällt (Tab. 8).

\section{Diskussion}

Untersuchungen des Fibrinogen- und Fibrinabbaus durch Bestimmung der Produkte der intravaskulären Proteolyse können wichtige Anhaltspunkte zur labordiagnostischen Abklärung von Störungen des hämostatischen Gleichgewichtes geben. Die Bestimmung von Fibrinogen- und Fibrinderivaten ist ein wichtiges laboranalytisches Instrument, wenn es um die Feststellung präthrombotischer Zustände, Diagnose und Verlaufskontrolle der Verbrauchskoagulopathie und der Kontrolle bzw. Steuerung der thrombolytischen Therapie geht. Dabei weisen die herkömmlichen Fibrin(ogen)-Spaltprodukt-Tests allerdings den Nachteil auf, aufgrund ihrer Antikörperbeschaffenheit nicht zwischen Fibrinogen- und Fibrinspaltprodukten differenzieren zu können. Neue Aspekte für die Diagnostik eröffnen sich durch die Verfügbarkeit von Tests zur spezifischen Bestimmung der Fibrinspaltprodukte (D-Dimere). Aus dem dargestellten Spektrum der Anwendung dieser neuen spezifischen Methoden ergeben sich zwei Erfordernisse: Die qualitative Aussage für Ja/Nein-Entscheidungen, wenn die rasche Diagnose im Vordergrund steht, und die quantitative Aussage für Verlaufsbeobachtungen und Spezialuntersuchungen. Mit $D$-Dimer-Test und ELISA D-Dimer wurden zwei neue Methoden hinsichtlich ihrer diagnostischen Validität untersucht, die die oben geforderten Kriterien erfüllen. Der Latex-D-Dimer-Test ist sehr einfach in der Anwendung und ermöglicht innerhalb von wenigen Minuten die qualitative $\mathrm{Ja} / \mathrm{Nein}$-Aussage über einen intravasalen Aktivierungsprozeß mit reaktiver Fibrinolyse. Da keine speziellen

Tab. 7: Methodenvergleich D-Dimer-Test-Dimertest Latex mit Plasmaproben von Patienten mit Verbrauchskoagulopathie

\begin{tabular}{llllll}
\hline $\begin{array}{l}\text { D-Dimer-Test (Boehringer) } \\
\mu g / m \text { Fibrinogenäquivalent } \\
\text { Dimer-Test Latex (Mabco) } \\
\mu \text { g/ml Fibrinogenäquivalent }\end{array}$ & $<20$ & $20-40$ & $40-80$ & $80-160$ & $160-320$ \\
\hline$<25$ & 0 & & & & \\
$25-50$ & 0 & 1 & 0 & 0 & 0 \\
$50-100$ & 0 & 2 & 1 & 1 & 0 \\
$100-200$ & 0 & 0 & 0 & 3 & 1 \\
$200-400$ & 0 & 0 & 0 & 1 & 0 \\
$>400$ & 0 & 0 & 0 & 0 & 0 \\
\hline
\end{tabular}


Tab. 8: Kreuzreaktion von D-Dimer-Test und Dimertest Latex mit verschiedenen Fibrinogen- und Fibrinderivaten

\begin{tabular}{|c|c|c|c|c|c|c|c|c|c|c|c|c|c|c|c|c|c|c|}
\hline \multirow{2}{*}{$\begin{array}{l}\text { D-Dimer-Konzen- } \\
\text { tration } \mu \mathrm{g} / \mathrm{ml} \\
\text { Fibrinogenäqui- } \\
\text { valent } \\
\text { Produkt }\end{array}$} & \multicolumn{9}{|c|}{ D-Dimer-Test } & \multicolumn{9}{|c|}{ Dimertest Latex (Mabco) } \\
\hline & 1000 & 100 & 50 & 10 & 5 & 2 & 1 & 0,5 & 0 & 1000 & 100 & 50 & 10 & 5 & 2 & $1 \mathrm{c}$ & 0.5 & 0 \\
\hline Fibrinogen & - & - & - & - & - & - & - & - & - & - & - & - & - & - & - & - & - & - \\
\hline $\begin{array}{l}\text { Frühe Fibrinogen- } \\
\text { spaltprodukte }\end{array}$ & - & - & - & - & - & - & - & - & - & - & - & - & - & - & - & - & - & - \\
\hline $\begin{array}{l}\text { Späte Fibrinogen- } \\
\text { spaltprodukte }\end{array}$ & \pm & \pm & \pm & \pm & - & - & - & - & - & + & + & + & \pm & - & - & - & - & - \\
\hline $\begin{array}{l}\text { FDP-D } \\
\text { (Fibrinogen) }\end{array}$ & \pm & \pm & \pm & \pm & - & - & - & - & - & \pm & ++ & + & + & \pm & - & - & - & - \\
\hline $\begin{array}{l}\text { FDP-E } \\
\text { (Fibrinogen) }\end{array}$ & - & - & - & - & - & - & - & - & - & - & - & $\overline{-}$ & - & - & - & - & - & - \\
\hline D-Dimer & +++ & +++ & +++ & ++ & ++ & ++ & + & \pm & - & +++ & ++ & ++ & + & + & \pm & $\pm=$ & \pm & - \\
\hline $\begin{array}{l}\text { Fibrin- } \\
\text { spaltprodukte }\end{array}$ & +++ & +++ & $++t$ & ++ & ++ & $+t$ & + & \pm & - & +++ & ++ & ++ & + & + & \pm & \pm & \pm & - \\
\hline
\end{tabular}

apparativen Voraussetzungen für die Testdurchführung erforderlich sind, eignet sich der D-Dimer-Test auch für das Notfallabor oder kann sogar als bed side-Methode auf der Station durchgeführt werden. D-Dimer-Konzentrationen oberhalb $0,5 \mu \mathrm{g} / \mathrm{ml}$ Fibrinogenäquivalente (Normal $<0,5 \mu \mathrm{g} / \mathrm{ml}$ ) werden zuverlässig angezeigt, $d . h$. ein positives Ergebnis ist immer ein Hinweis auf einen Aktivierungsprozeß. Sowohl als qualitativer Schnelltest wie auch als semiquantitative Bestimmung zeichnet sich die Methode durch eine sehr gute Präzision und Wiederfindung aus. Da bei Latex-Tests im Normalfall auf eine Standardisierung verzichtet wird, ist die Chargenunabhängigkeit von Empfindlichkeit und Präzision ein entscheidendes Zuverlässigkeitskriterium. Der Vergleich mehrerer Reagenzchargen zeigte, daß keine chargenbedingten Differenzen im Agglutinationsverhalten auftreten und damit bei Chargenwechsel keine Unsicherheiten in der Beurteilung zu befürchten sind. Kreuzreaktionen mit Fibrinogen und Fibrinogenderivaten wurden mit Ausnahme von FDP-D nicht beobachtet. Da unter physiologischen Bedingungen ein Fibrinogenabbau durch die Wirkung von $\alpha_{2}$-Antiplasmin auf die frühen Spaltprodukte beschränkt bleibt, hat diese Kreuzreaktion keinen Einfluß auf die Testaussage, d.h. der D-Dimer-Test ist spezifisch für den Nachweis von Fibrinspaltprodukten. Im Methodenvergleich D-Dimer-Test-Dimertest Latex (Mabco) wurden gute Übereinstimmungen gefunden. Die Ergebnisse mit dem D-Dimer-Test (Boehringer Mannheim) weisen auf eine bessere Abstufung im Grenzbereich normal-pathologisch hin. Da dieser Befund für den Einsatz der Methode als Screening-Test von besonderer Bedeutung ist, ist eine entsprechende Untersuchung an einem größeren Patientenkollektiv vorzunehmen. Beim Vergleich der Kreuzreaktionen wurde bei $D$-Dimer-Tests eine geringere Beeinflussung durch Fibrinogenderivate festgestellt.

Für ELISA D-Dimer gelten bezüglich Kreuzreaktion mit Fibrinogen und Fibrinogenderivaten die gleichen Aussagen wie für D-Dimer-Test. Weitere Merkmale sind: gute Präzision mit einem Variationskoeffizienten von 1,6$2,1 \%$ in der Serie, Linearität des Testsystems von 10 $1000 \mathrm{ng} / \mathrm{ml}$ (bei Plasmavorverdünnung 1:20) und hohe Empfindlichkeit $(0,5 \mathrm{ng} / \mathrm{ml})$. Methodische Vorteile bietet die Möglichkeit, das Trägermaterial für die Immunreaktion selbst zu wählen und somit die Testdurchführung an die apparativen Gegebenheiten im Labor anzupassen.
D-Dimer-Test und ELISA D-Dimer sind praktikable Methoden zur spezifischen Bestimmung der D-Dimere. Die Verwendung von Citratplasma als Probenmaterial ohne Einfluß von Fibrinogen erhöht die Praktikabilität und die Zuverlässigkeit der Spaltproduktbestimmung erheblich. Durch die Verfügbarkeit von zwei in ihrer Durchführung und Aussage. sich ergänzenden Methoden, D-DimerTests zum schnellen Screening im Notfall und Routine, ELISA D-Dimer zur quantitativen Bestimmung und Verlaufskontrolle, können die diagnostischen Möglichkeiten der D-Dimer-Bestimmung voll ausgeschöpft werden. Die einfache Durchführung ermöglicht einem breiten Anwenderkreis die D-Dimer-Bestimmung und ist nicht mehr auf wenige Speziallabors beschränkt.

Schrifttum:

1. DELVOS, U., MÜLLER-BERGHAUS, G.: Die Regulation der Blutgerinnung. Naturwissenschaften 72, $461-469$ (1985).

2. STORMORKEN, F. The inherited basis for venous thrombosis - The thrombohaemorrhagic balance. Scand J. Haematol. 34, 353-359 (1985).

3. NIEUWENHUIZEN, W: The use of monoclonal antibodies in demonstrating different fibrinogen derivates. In: Fibrinogen and its derivates. Müller-Berghaus, G., Scheefers-Borchel, U., Selmayr, E., Henschen, A. (eds.). Excerpta Medica, Amsterdam, pp. 245-256 (1986).

4. MAMMEN, E. F.: Congenital coagulation disorders. Sem. Thromb. Haemost. 9, 1 13 (1983).

5. LASCH, H. G., heENE, D. L., HUTH, K., SANDRITTER, W.: Pathophysiology Clinical manifestation and therapy of consumption coagulopathy ("Verbrauchskoagulopathie"). Am. J. Cardiol. 20, 381-391 (1967).

6. MÜLLER, J., TRÜBESTEIN, G.: Fibrinolyse heute: Therapie mit Urokinase und Streptokinase. Die gelben Hefte XXII, 60-68 (1982).

7. NIEUWENHUIZEN W. Assay of fibrinogen/fibrin degradation products and their clinical relevance. Fibrinogen Workshop (Scotland) 1987.

8. ECKHARDT, Th.: Die Bestimmung des Fibrinopeptids $A$ als Thrombinindikator bei Krankheitszuständen mit aktivierter, intravaskulärer Gerinnung. In: Neue Aspekte der Gerinnungsdiagnostik, Hrsg.: Róka, L., Spanuth, E. Schattauer Verlag, Stuttgart, New York, pp. $91-108$ (1984).

9. OEHLER, G. KLAUS: H, STOTZER K.-E, SPANUTH, E.: Der Nachweis von löslichen Fibrinmonomer-Komplexen. Methodenvergleich eines Erythrozyten-Agglutinationstests nach Largo (FM-Test) mit dem Ethanol-Gelierungs-Test. Lab.med. 11. 25-30 (1987).

10. FRANKE, M., HAFTER, R., VON HUGO, R., RÖBL, M., GRAEFF, H.: Ein Test zUm Nachweis von Fibrin im Plasma. Geburts- und Frauenheilkunde 36, 105-109 (1986). 11. MERSKEY, C LALEZARI, P JOHNSON A J. A rapid simple, sensitive method for measuring fibrinolytic split products in human serum. Proc. Soc. Exp. Biol. Med. $131,871-875$ (1969)

12. HAWIGER, J., NIEWIAROWSKI, S.; GUREWICH, V., THOMSON, D. P.: Measurement of fibrinogen degradation products in serum by staphylococcal clumping test. J. Lab. Clin. Med. 75, 93-97 (1970).

13. SPANUTH, E AMIRAL J.: Diagnostische Validität eines neuen Latex-Agglutinations-Tests zur Bestimmung von Fibrin (ogen)-Spaltprodukten (FDP-Test). Lab.med. 8, 347-350 (1984) 
14. AMIRAL, J., ADALBERT-BIRON, B., CANTON, M.: Measurement of D-Dimer with an Enzyme-Immuno-Assay. IVth International Meeting of Danubian League Against Thrombosis and Hemorrhagic Diseases, Istanbul, 25. - 28. September (1985) 15. GAFFNEY, P. J., FRANKLIN, J.: The lysis of crosslinked human fibrin by plasmin vields initially a single molecular complex D-Dimer-E. Thromb. Res. 15, 673-687 (1979).

16. GAFFNEY, P. J.: Fibrin fragmentation by Plasmin: molecular considerations and their relevance to DIC and thrombosis. In: Fibrinogen-Recent Biochemical and Medical Aspects, Henschen. A., Graeff, H., Lottspeich, F. (eds.). W. de Gruyter, Berlin. Now York, pp. 407-423 (1982).

17. SCHROCK, R., HAFTER, R., SCHMID, L, BABIC, R., ULM, K., GOSSNER, W. GRAEFF, H.: Tumorassoziierte Antigene und Fibrinderivate als Reaktionsprodukte des Ovarialkarzinoms. Geburts- und Frauenheilkunde 46, 1-10 (1986).

18. BLOMBACK, B., BLOMBACK, M.: Purification of human and bovine fibrinogen. Archiv for Kemi 10, 415-443 (1956).

19. MARDER, V. J., JAMES, H. L., SHERRY, S.: The purification of fibrinogen degradation products by PEVIKON block electrophoresis. Thromb. Diath. Haemorr. 22. 234-239 (1969).

20. AMIRAL, J., PLASSART, V., MINARD, F.: Measurement and Clinical Relevance of D-Dimer by ELISA. In: Fibrinogen and its derivates, Müller-Berghaus, G., ScheefersBorchel, U., Selmayr, E., Henschen, A. (eds.). Excerpta Medica, Amsterdam, pp. 285290 (1986).

21. GAFFNEY, P. J.: Fibrinolyses by Plasmin and Brinase.In Vitro and in Vivo Observations. In: Progress in Chemical Fibrinolysis and Thrombolysis, Vol. 3. Davidson, J. F., Rowan, R. M., Samama, M. M., Desnoyers, P. C. (eds.). Raven Press, New York pp. $343-372$ (1978).

Anschrift für die Verfasser:

Dr. Karl-Eugen Stötzer Boehringer Mannheim GmbH Abteilung Blutgerinnung Sandhofer Straße 116 6800 Mannheim 31

\section{FIBRINMONOMERE PHOTOMETRISCH BESTIMMEN}

Fibrinmonomere t-PA

I

Plasminogen

II

Plasmin

$\mathbb{1}$

H-D-Val-Phe-Lys + pNA
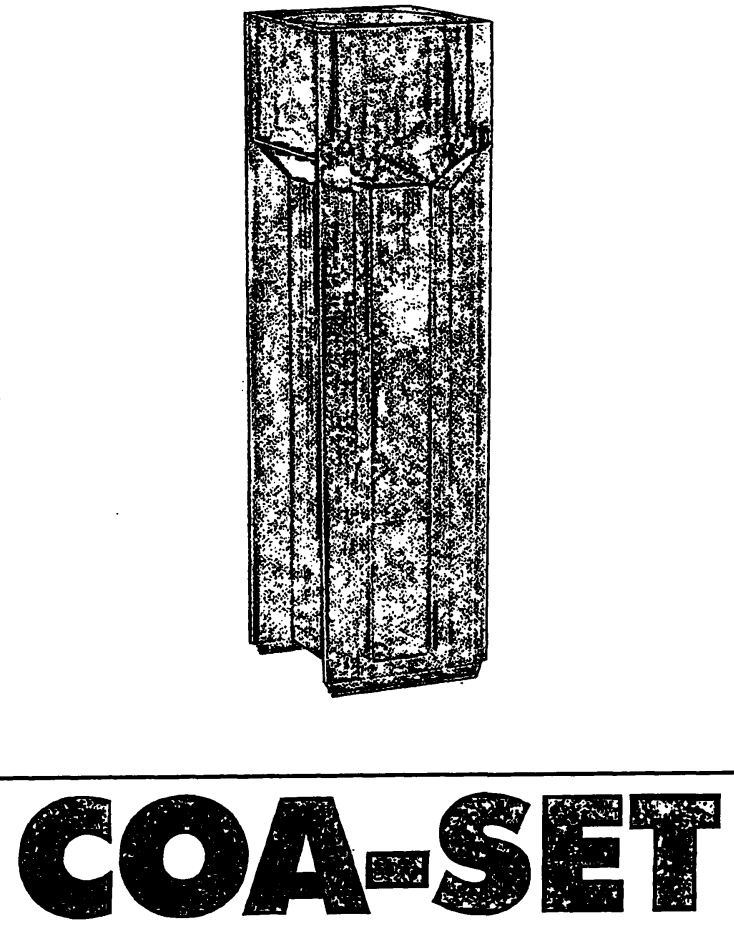

FIBRINMONOMER Deutsche KabiVitrum GmbHö 8000 München 80
8000

. Levelingstraße 18

Telefon 089 / 4 31 93-0 